\title{
Hernán Cortés, a través de algunos cronistas e historiadores de Indias
}

$\mathbf{E}^{\mathrm{N}}$ la historia de la conquista de América no hay figura tan discutida como la de Cortés. Para ciertos cronistas es un genio digno de toda alabanza, para otros es un bandido criminal. Unos acèntúan sus defectos, su crueldad, su codicia, su hipocresía, su a fán de gloria y de poder; otros sus dotes de capitán noble y justo, su valor, su tenacidad, su genio de diplomático y guerrero que lleva a cabo la empresa más grande de América con un puñado de españoles.

Dice el historiógrafo Ramón Iglesia: "A partir del momento mismo en que se realizó (la conquista), desde que Cortés escribió a Carlos V las cartas en que daba noticia de su empresa, conforme ésta se iba desarrollando, hasta hoy, se han escrito sobre la conquista de México, en todos los lugares y en todas las lenguas, libros, artículos, comentarios inspirados en los puntos de vista más opuestos. La cultura, la religión, la nacionalidad, la raza, han entrado en juego para que se juzgue de manera muy diversa la conquista y las personas y pueblos que en ella intervinieron". ${ }^{1}$

Examinemos los orígenes de esta diversidad de corrientes.

No se puede enfocar claramente la personalidad de Cortés, y no podremos comprender sus móviles y su carácter, sin tener en cuenta sus Cartas de relación al Emperador Carlos V. En estas cartas, de estilo sobrio, terso y altamente digno, encontramos el retrato de un Cortés majestuoso, noble y leal a su rey, cuyos ideales son los de un caballero cristiano renacentista, que era a la vez un bravo guerrero, y como español, un defensor y propagador de su fe que encuentra la justificación de guerras y conquistas de nuevas naciones en la conversión de los infieles a la única fe verdadera. 
Sus móviles eran, según él, el acrecentamiento de los dominios españoles, la propagación de la fe católica, la adquisición de gloria y fama. Cuando sus soldados vacilan y dudan del éxito de la empresa, nos dice: "yo los animaba diciéndoles que mirasen que eran vasallos de V. A. y que jamás en los españoles en ninguna parte hubo falta, y que estábamos en disposición de ganar para V. M. los mayores reinos y señoríos que había en el mundo. $\mathrm{Y}$ que demás de facerlo, que como cristianos éramos obligados en puñar contra los enemigos de nuestra fe, y por ello en el otro mundo ganábamos la gloria, y en éste conseguíamos el mayor prez y honra que hasta nuestros tiempos ninguna generación ganó". ${ }^{2}$

Escribe también al Emperador: "Con todà la justicia que puedo y debo, exhorto y ruego a todos los españoles que en mi compañia fueren a esta guerra que al presente vamos, y a todas las otras guerras y conquistas que en nombre de S. M. por mi mandado hubieran de ir, que su principal motivo e intención sea apartar y desarraigar de las dichas idolatrías a todos los naturales destas partes y reducillos al conocimiento de Dios y de su santa fe; porque si con otra intención se hiciere la dicha guerra, sería injusta". ${ }^{3}$

Sabemos que había otro móvil que animaba también a Cortés y a sus compañeros: el deseo, la esperanza de obtener riquezas, oro, botín. Aunque este motivo no lo vemos francamente expresado en las cartas de Cortés, sabemos que el oro y las riquezas eran considerados por los conquistadores como consecuencia natural de toda victoria y subyugación de los pueblos conquistados, como premio de sus trabajos y batallas, y también para acrecentar el tesoro del Emperador, en cuyo nombre se pretendía hacer la conquista.

Entre los actos de crueldad que se le achacan a Cortés sobresalen el castigo de los emisarios de Tlaxcala, la matanza de Cholula, y la muerte de Cuauhtémoc. Cortés relata estos hechos con una impasibilidad que sorprende al lector moderno; para él estaban justificados como medidas necesarias para la protección y defensa de su ejército y el éxito de la magna empresa a que se había dedicado.

A los espías de Tlaxcala, después de obtener la confesión de su delito, dice que "los mandé tomar a todos cincuenta y cortarles las manos; y los envié que dijesen a su señor que de noche y de día y cada y cuando él viniese vería quién eramos". " 
Al saber la emboscada que le tenían preparada los de Cholula, se vale de una estratagema para salvar las vidas de los españoles y para castigar a los indios: "dímosles tal mano que en dos horas murieron más de tres mil hombres... como los tomamos de sobresalto fueron buenos de desbaratar, mayormente que les faltaban los caudillos; porque los tenía yo presos".

Estos incidentes eran para Cortés necesarios para el buen éxito de la guerra, aunque sólo recurría a ellos cuando su política de atracción pacífica no obtenía resultados.

De las Cartas de Cortés saca el lector una idea muy alta del genio militar y político del caudillo de la conquista; alli se reflejan su astucia, su diplomacia, su don de gentes, su valor, su lealtad a la corona, y su propósito de crear una nación grande, próspéra y cristiana, de lo que era antes un pueblo idólatra. Le seduce la tierra que va a conquistar y una vez conquistada la ama. Alaba y admira siempre el valor y capacidad de los mexicanos. Cuando ha logrado la pacificación del pais, quiere que se olvide la sangre derramada, que se restablezca la vida normal y próspera, mejor que la que había habido antes de la conquista. Dicta medidas para la protección y buen gobierno de los naturales, y para que los españoles arraiguen y se establezcan en el pais, en vez de abandonarlo después de haberlo despojado de sus riquezas.

Este amor e interés que manifiesta en el porvenir de México llega hasta la hora de su muerte, en España, cuando dispone en su testamento que su cuerpo reciba sepultura en México. Para él, México, la Nueva España creada por sus hazañas y sus victorias era su patria. A ella confia sus huesos. El conquistador había sido conquistado.

Esta visión del Cortés heroico y noble fué continuada y llevada a un grado superlativo por su biógrafo y panegirista, Francisco López de Gómara, cuya Historia de las Indias, por lo que a México se refiere, es una glorificación, una biografía-panegírico de Cortés. La obra de Gómara, publicada en 1552, es la primera que aparece sobre el tema de México. Desde el primer momento fué discutida, censurada, recogida por algún tiempo, se siguió reimprimiendo $\mathrm{y}$ fué traducida a varios idiomas. Gómara era un renacentista que sentía él mismo el ansia de inmortalidad, y que dedicó todas sus 
obras históricas a ensalzar y conservar para la generaciones futuras las proezas de héroes, de hombres grandes en las armas y en las letras. Gómara entró como capellán al servicio de Cortés, cuando éste se encontraba en España reclamando sus derechos en la corte del Emperador, y no le abandonô hasta su muerte. (1547) Es de suponer que durante estos años recogió de labios de Cortés y tomó de sus cartas y papeles los datos para su Historia. Si para la mentalidad renacentista Cortés era el guerrero invencible digno de loa inmortal, nada más justo que Gómara, dotado de sólida y extraordinaria cultura renacentista, fuera su biógrafo.

Cuando éste escribía su Historia, habían pasado ya los días de la próspera fortuna de Cortés. Sus enemigos le habían acusado ante el Emperador, primero de deslealtad a la corona, luego de injusticias, de ambiciones, codicia y mala administración. El prestigio de Cortés, antes tan alto, había disminuído mucho, por las intrigas de émulos, descontentos y envidiosos. Gómara, caballero andante de la pluma, reivindica al caballero-guerrero sin tacha, llegando en ocasiones a imputar al Emperador ingratitud hacia el héroe que enriqueció su corona con una Nueva España.

No es de extrañar, pues, que la visión de Cortés que nos da Gómara sea la de un héroe; héroe a veces con pequeñas imperfecciones de hombre, pero héroe al fin. La obra de la conquista se debió a su genio militar, a su diplomacia, a sus dotes de persuasión, a su valor, y también -aunque sólo sea entre paréntesis- a sus soldados. La propagación de la fe y la conversión de los infieles justifican sus actos. Cortés es un caudillo providencial, que tiene el don de convencer, atraer y animar a todos sus compañeros al mismo tiempo que se hace amar de ellos. Nos dice: "Con este razonamiento puso Fernando Cortés en sus compañeros gran esperanza de cosas y admiración de su persona. $\mathrm{Y}$ tanta gana les tomó de pasar con él a aquellas tierras apenas vistas, que les parecía ir no a guerra, sino a vitoria y presa cierta". $\mathrm{Y}$ en otra parte: "Todos quedaron contentos del razonamiento de Cortés. Los que flaqueaban esforzaron. Los esforzados cobraron doble ánimo. Los que algún mal le querian comenzaron a honrarlo. $Y$ en conclusión, él fué de alli en adelante muy amado de todos aquellos españoles de su compañia". 
Pone muy alto el fervor religioso y celo evangélico de Cortés. Quizá para acentuar la justicia de las severas medidas que tendrá que adoptar Cortés muy pronto, nos lo presenta en aspecto misionero: "Viendo, pues, que guardaban justicia y vivían en religión, aunque diabólica, siempre que Cortés les hablaba, les predicaba con los farautes, rogándoles que dejasen los ídolos y aquella cruel vanidad que tenían matando y comiendo hombres sacrificados".

Las medidas severas, los castigos crueles están justificados por el gran peligro que corrían los españoles de perder sus vidas: "En grandísimo peligro estaban los nuestros, así de perder a México como las vidas, si no se atajara esta guerra y motín".

"¿Qué fama, que loa será la de Cortés? El quitó los ídolos, el predicó, él vedó los sacrificios y tragazón de hombres". 5 Sólo cuando nos narra la muerte de Cuauhtémoc, aminora un poco la nota de alabanza y aparece su admiración por el héroe indio. Aunque cree, como lo creyó Cortés, que Cuauhtémoc había preparado una sublevación contra Cortés para recobrar su reino y deshacerse de los españoles y que, por lo tanto, su sentencia de muerte era técnicamente justa, ve en Cuauhtémoc otro héroe que no debía de haber terminado en la horca. "Fué Cuauhtémoc, dice, valiente hombre, y en todas sus adversidades tuvo ánimo y corazón real: tanto al principio de la guerra, para la paz, cuanto en la perseverancia del cerco; y así cuando le prendieron, como cuando le ahorcaron, y como cuando; porque dijese del tesoro de Moctezuma, le dieron tormento. El cual fué untándole muchas veces los pies con aceite y poniéndoselos luego al fuego. Pero más infamia sacaron que no oro. $\mathrm{Y}$ Cortés debiera guardarlo vivo como oro en paño, que era el triunfo y gloria de sus vitorias; mas no quiso tener que guardar en tierra y tiempo $\tan$ trabajoso". ${ }^{6}$

En oposición a Gómara está el P. Bartolomé de Las Casas.

Para este defensor infatigable de los indios, la conquista no tiene justificación alguna, $\mathrm{y}$ todos los que tomaron parte en ella, empezando por Cortés, fueron avariciosos, crueles e infames. Los indios eran seres casi perfectos, inocentes y pacíficos. Sólo un motivo impulsó la conquista: la codicia, "porque dél y dellos (de Cortés $y$. de sus soldados) eran sólo un fin, y éste no otro sino hacerse ricos de la sangre de aquestas míseras y humildes pacíficas gentes". Arremete contra Gómara y los amigos de Cortés, de los cuales dice 
que "todo lo que escribieron no va enderezado sino a excusar las tiranías y abominaciones de Cortés, como las de los demás, y en abatimiento de los tristes y desamparados indios". Se ve, pues, que Las Casas era enemigo declarado de Cortés y ataca violentamente a sus panegiristas: "Gómara, clérigo, que escribió la historia de Cortés, que vivió con él en Castilla siendo ya marqués, y no vido cosa ninguna, ni jamás estuvo en las Indias, y no escribió cosa sino lo que el mismo Cortés le dijo, compone muchas cosas en favor de él que cierto no son verdad". ?

E1 celo religioso de Cortés, cuando destruye los ídolos e impone el culto de las imágenes cristianas, no es más que disparate $\mathrm{e}$ imprudencia, según Las Casas: "Dice aquí Gómara que Cortés determinó de quitar los ídolos de aquel pueblo y poner cruces en aquella isla ...; pero este es uno de los errores y disparates que muchos han tenido y hecho en estas partes, porque sin primero haber a los indios y a cualquier nación idólatra doctrinado, es gran desvarío quitarles los ídolos ..." 8

Las Casas, poseído de la idea apriorística de la bondad de los indios llega hasta negar que éstos sacrificaran hombres y se los comieran, considerando estos relatos como excusas para justificar la conducta de Cortés: "Esto de sacrificar hombres y comerlos, como dice Gómara, yo creo que no es verdad, porque siempre oí que en aquel reino de Yucatán ni hobo sacrificios de hombres ni se supo qué cosa era comer carne humana, y decirlo Gómara, como ni lo vido ni lo oyó sino de boca de Cortés, su amo, y que le daba de comer, tiene poca autoridad, como sea en su favor $\mathrm{v}$ en excusa de sus maldades, sino que esto es lenguaje de los españoles y de los que escriben sus horribles hazañas, infamar todas estas universas naciones para excusar las violencias, crueldades, robos y matanzas que les han hecho, y cada día y hoy les hacen." Termina Las Casas: "Veis aquí con qué tiene Cortés engañado a todo el mundo, y no sin culpa de muchos de los que lean su falsa historia, no considerando que aquellos (los indios) estaban quietos en sus casas, sin ofensa nuestra ni de nadie, y que no eran moros ni turcos que nos infes$\tan$ y nualtratan, no mirando más del sonido que mató y venció, y como ellos dicen, conquistó tantas naciones, y robó para sí e envió tanto oro a España, y llegó a ser marqués del Valle." 9 
Las acusaciones y exageraciones de Las Casas se esparcieron por Europa y fueron acogidas como dogma de fe por los enemigos de España; sobre todo, en países protestantes. Empieza así la corriente de denigración contra los españoles, lo que se ha venido a llamar la "leyenda negra".

Pero en México también quedaron descontentos y resentidos contra Cortés, no sólo entre los españoles, sino también -y esto es significativo - entre los descendientes de los nobles mexicanos subyugados. Estos, aunque cristianos ya y súbditos de la corona española, no olvidaron los excesos militares y medidas crueles que tuvo que adoptar Cortés en los días de crisis guerrera.

De los escritores indígenas que dejaron sus memorias en lengua castellana, sirva de muestra don Fernando de Alva Ixtlilxóchitl, descendiente del noble Ixtlilxóchitl de Texcoco que participó en todas las expediciones de Cortés desde la segunda marcha sobre México. Don Fernando, en su Décimatercia relación de la venida de los Españoles, acusa a Cortés de ingratitud por no haber reconocido públicamente la gran parte que sus aliados texcocanos tuvieron en la conquista de México, sin la cual difícilmente hubiera podido hacerse. Se queja varias veces de la crueldad de Cortés, como cuando nos dice que su padre Ixtlilxóchitl "no pudo sufrir la crueldad de Cortés y le dijo que le hiciese placer de quitar del tormento al criado del rey Cuauhtémoc, pues sabía claramente que era en vano cuanto hacía y gran inhumanidad, que así daba ocasión a que se tornasen a rebelar. Cortés conociendo su inhumanidad y el riesgo tan grande que corría lo mandó soltar." 10 No se le perdonará a Cortés nunca la injusticia que comete al mandar ahorcar a Cuauhtémoc y a los otros reyes y señores, camino de las Hibueras: "Y así claro parece de las historias, pinturas y demás relaciones, y confesión de este indio y a quien Cortés pone por testigo, que murieron estos señores sin culpa; mas a la verdad, fingiendo todas estas cosas por quitarse de embarazo, y que no quedase señor natural en la tierra". Encarece también don Fernando la codicia de Cortés y los suyos, el afán de gloria y las injustas muertes de los nobles mexicanos. El lamento a la muerte de los reyes y nobles es una nota que se prolonga y perdura, con razón o sin ella, en la conciencia del mexicano: 'Cortés los mató sin culpa, sólo porque la tierra quedase sin señores naturales; el cual si conocía tanto bien como Dios le había hecho, los 
había de tener sobre sus ojos, y estimarlos como piedras preciosas, que era el triunfo de sus hechos; pero él siempre procuró de matar a los señores, $\mathrm{y}$ aun a sus nietos, $\mathrm{y}$ obscurecer sus glorias, $\mathrm{y}$ dárselas a sí solo, porque si se mira bien, si él únicamente y .sus compañeros sujetaran toda la tierra, fuera imposible." 11

Pero el que más reparos puso a la obra de Gómara, fué Bernal Díaz del Castillo.

Este soldado de las campañas de México, escribió, ya viejo, desde su retiro de Guatemala, su Historia verdadera de la Conquista de Nueva España; "en respuesta - escribe- de lo que han dicho y escrito personas que no lo alcanzaron a saber ni lo vieron ni tener noticia verdadera de lo que sobre esta materia hay."

Se refiere a Gómara, cuya Historia encuentra llena de errores e inexactitudes.

Según el cotejo hecho por el historiógrafo Iglesia, estos errores son de poquísima monta o existen solamente en la cabeza del buen Bernal. La causa de la insatisfacción de Bernal Díaz es otra. Gómara concebía la historia de los grandes hechos del mundo y en particular los de la conquista de México, como la historia de los hombrescaudillos. Lo demás era subordinado y debía quedar en sombra. Bernal la ve desde un punto de vista personal del soldado que tomó parte en las batallas y que considera la victoria como fruto de sus esfuerzos individuales. La conquista de México, nos repite, fué hecha por "nosotros, los soldados y capitanes" y no sólo por Cortés. este se guiaba y aconsejaba por ellos, y casi recibimos la impresión de que Cortés no dió paso ni tomó medida que no fuera aprobada o recomendada por sus soldados. Le irritaba leer en Gómara que a Cortés se le debía todo, puesto que "Cortés, dice, ninguna cosa decía ni hacía, sin primero tomar sobre ello muy maduro consejo $y$ acuerdo con nosotros, puesto que el coronista Gómara diga 'hizo Cortés esto, fué allá vino de acullá, y dice otras tantas cosas que no llevan camino, y aunque Cortés fuera de hierro, según lo cuenta Gómara en su historia, no podía acudir a todas partes." 12

Dedica, pues, Bernal Díaz su Historia verdadera a reivindicar y dar por bien establecida su parte y la de sus compañeros en la conquista de México. A pesar de esto, se ve en toda la obra una gran admiración a Cortés, aunque no tanta que le cierre los ojos para no ver sus defectos. Le acusa en primer lugar de que en sus. 
cartas al Emperador se alaba demasiado a sí mismo y no da importancia alguna a sus soldados. "Y esto digo que cuando Cortés a los principios escribía a su Majestad, siempre por tinta le salían perlas y oro de la pluma, $y$ todo en su loor, y no de nuestros valerosos soldados" y "no curó de demandar cosa ninguna para nosotros que bien nos hiciese, sino solamente para él." 13 Reconoce su codicia de riquezas y oro, aunque esta calidad no es grave para Bernal, pues él mismo la tenía, como también los demás soldados; después de todo, el ansia de riquezas y de mejoramiento personal era uno de los objetos secundarios de toda exploración y conquista. Nos habla de su astucia, de su arte de persuasión, de su diplomacia, a veces, es verdad un poco turbia, pero siempre guiada por altos fines; de sus dotes de orador, $y$ es el único cronista que nos ha dejado testimonio de cómo se las arreglaba Cortés para que las decisiones graves y peligrosas que él concebía parecieran salir de sus capitanes y soldados, a las cuales accedía a estilo democrático. "Por manera - dice en una ocasión- que Cortés lo aceptó, y aunque se hacía mucho de rogar, y como dice el refrán tu me lo ruegas y yo me lo quiero, y fué con condición que le hiciesemos justicia mayor y capitán general, y lo peor de todo que le otorgamos que le diesemos el quinto de oro de lo que hobiese, después de sacado el real quinto..." 14 Aunque Bernal Díaz escribió su Historia para realzar su propia parte en la conquista y quitarle así a Cortés la exclusiva gloria que le daba Gómara, no por eso deja de aparecer Cortés como hombre grande en las páginas por él escritas. Cuanto más trata Bernal de engrandecer al soldado raso, tanto más resplandece la figura y genio de Cortés. Solamente en casos raros, como por ejemplo en el incidente de la muerte de Cuauhtémoc, tiene palabras de desaprobación. "Y fué esta muerte que les dieron, escribe, muy injustamente dada, y pareció mal a todos los que ibamos a aquella jornada" (de las Hibueras). Pero no acusa a Cortés de crueldad; al contrario, nos recuerda que "cuando Cortés firmó aquella sentencia, dijo con grandes sospiros y sentimientos 'oh quien no sopiera escribir por no firmar muertes de hombres'." 15

En resumen, Bernal descuenta la mitad de las alabanzas que Gómara hace de Cortés, reclamándolas para los soldados como él, que llevaron el peso de la campaña. Fuera de esto, Cortés fué el caudillo genial, para el cual no escatima las alabanzas, y al cual da el 
testimonio más grande de lealtad que un soldado puede dar a su jefe: "y todos nosotros pusieramos la vida por el Cortés". ${ }^{16}$

Ha dicho el historiador Prescott que las dos columnas sobre que descansa la historia de la conquista de México, son estas dos obras de Gómara y de Bernal Díaz. En tiempos recientes se ha querido rebajar el lustre de Cortés dando una importancia hasta aquí inusitada al relato humilde, ingenuo y cautivante del simpático soldado. Las ediciones de su Historia se han multiplicado en nuestros días, mientras que la obra de Gómara está casi olvidada, y sólo es consultada y apreciada por los estudiosos o amantes de la España imperial.

Si es verdad que las exageraciones y acusaciones injustas del $P$. Las Casas han sido rectificadas hoy por casi todos los historiadores modernos - Merriam, McNutt, Bourne, etc--, los residuos de su propaganda anticortesiana quedan todavía en la mente colectiva de ciertos sectores americanos. Quizás el alza de la historia de Bernal en nuestros días y la baja de los valores de Gómara se deban a substrato que enterró Las Casas en la historia y también al resentimiento contra Cortés, representado por don Fernando Alva Ixtlilxóchitl, que ha permanecido secretamente en los recodos misteriosos de la conciencia, en México.

La ironía de la fortuna quiso que Cortés, que con amor de padre creara la nueva nación mexicana y que a ella encomendó sus restos mortales, pues era su patria adoptiva, no haya recibido en aquella tierra hasta hoy el honor de una estatua. Parece que Cuauhtémoc le venciera con su muerte; así lo proclama la estatua de este héroe azteca, desde su pedestal, en una de las avenidas principales de la ciudad de México.

Hermenegildo Corbató, University of California at Los Angeles.

$N O T A S$

1 Ramón Iglesia, Cronistas e historiadores de Indias. México, 1042, pp. $11-12$.

2 Ibid., p. 32. 
3 Ibid., pp. 42-43.

4 Ibid., p. 30.

5 "Ibid., pp. 166 y 183.

6 Ibid:, pp. 208-209.

7 Ibid., pp. 133, 136.

8 Ibid., p. 137. Un punto de vista diametralmente opuesto al de Las Casas, sobre este particular, se encuentra en "Motolinía". Carta al Emperador Carlos $V$, del 2 de enero de 1555 (Colección de Documentos Inéditos, publicada por Joaquín García Icazbalceta. México, 1855).

9 Ibid., p. 138.

10 Fernando de Alva Ixtlilxóchitl, Décimatercia relación de la venida de los españoles y principio de la ley evangélica, Editorial Robredo. México, 1938, p. 50 .

11 Ibid., p. 86.

12 Bernal Díaz del Castillo, Historia verdadera de la conquista de la Nueva España, ed. de Genaro Garcia. México, 1904, tomo I, p. 4.

13 Ibid., p. 143.

14 Ibid., p. 121.

15 Ibid., p. 164.

16. Ibid., p. 68. 
